\title{
AVALIAÇÃO DA QUALIDADE NUTRICIONAL DA LEUCENA EM BANCO FORRAGEIRO DE CORTE NO SUDESTE DO PARÁ
}

\author{
Karolinny Carneiro Guerra Costa ${ }^{1}$; Rosana Quaresma Maneschy ${ }^{2}$; Albinei Araújo de \\ Castro $^{3}$; Tatiane Pereira Guimarães ${ }^{4}$; Ilmaione Keiza de Souza Oliveira ${ }^{5}$. \\ ${ }^{1}$ Discente de Agronomia da UFPA - Campus de Marabá, karolinnycg.guerra@gmail.com \\ ${ }^{2}$ Prof. ${ }^{a}$, DSc. da UFPA - Campus de Marabá, romaneschy@ufpa.br \\ ${ }^{3}$ Discente de Agronomia da UFPA - Campus de Marabá, Bolsista FAPESPA, albinei@ hotmail.com \\ ${ }^{4}$ Discente de Agronomia da UFPA - Campus de Marabá, Bolsista FAPESPA, tatianepg.ufpa@ gmail.com \\ ${ }^{5}$ Discente de Agronomia da UFPA - Campus de Marabá, Bolsista PIBIC/PARD, ilmaionekeiza@ hotmail.com
}

\begin{abstract}
RESUMO: A utilização de bancos forrageiros de espécies lenhosas tem sido utilizada como uma alternativa sustentável para alimentação animal. O estudo foi realizado no assentamento Belo Horizonte I, no município de São Domingos do Araguaia - PA. Objetivou-se avaliar a qualidade nutricional da leucena (Leucaena leucocephala) em banco forrageiro de corte. O plantio das mudas foi realizado em fileiras espaçadas $1 \mathrm{~m}$, com $3 \mathrm{~m}$ entre plantas. Para a avaliação foi realizado o corte das plantas a $70 \mathrm{~cm}$ do solo em março de 2010. As amostras foram separadas em fração não utilizável (caule $\geq 1 \mathrm{~cm}$ ) e utilizável (folhas, vagem e galhos $\leq 1 \mathrm{~cm}$ ) para a determinação do teor de proteína bruta $(\mathrm{PB})$, fósforo $(\mathrm{P})$, cálcio $(\mathrm{Ca})$, magnésio $(\mathrm{Mg})$, cobre $(\mathrm{Cu})$, Ferro $(\mathrm{Fe})$, manganês $(\mathrm{Mn})$ e zinco (Zn). A avaliação da leucena durante o período chuvoso do ano demonstrou que a fração utilizável dessa forrageira atendeu aos requerimentos mínimos de $\mathrm{PB}, \mathrm{P}, \mathrm{K}, \mathrm{Ca}, \mathrm{Mn}$ e Fe para bovinos de corte em fase de lactação.
\end{abstract}

PALAVRAS-CHAVE: leguminosa forrageira, Leucaena leucocephala, sistema silvipastoril.

\section{EVALUATE THE NUTRITIONAL QUALITY OF LEUCAENA IN BANK FODDER CUTTING IN SOUTHEAST PARÁ}

\begin{abstract}
The use of fodder banks of woody species has been used as a sustainable alternative to animal feed. The study was conducted in the settlement Belo Horizonte I, in São Domingos do Araguaia - PA. The objective was to evaluate the nutritional quality of leucaena (Leucaena leucocephala) in bank fodder cutting. The planting of seedlings was carried out in rows spaced $1 \mathrm{~m}$ with $3 \mathrm{~m}$ between plants. For the evaluation were harvested from plants at $70 \mathrm{~cm}$ soil in March 2010 . The samples were separated in not usable fraction ( $\mathrm{stem} \geq 1 \mathrm{~cm}$ ) and usable (leaves, pods and twigs $\leq$ $1 \mathrm{~cm})$ for the determination of crude protein $(\mathrm{CP})$, phosphorus $(\mathrm{P})$, calcium $(\mathrm{Ca})$ magnesium $(\mathrm{Mg})$, copper $(\mathrm{Cu})$, iron $(\mathrm{Fe})$, manganese $(\mathrm{Mn})$ and zinc $(\mathrm{Zn})$. Evaluation of leucaena during the rainy season demonstrated that the usable fraction this forage met the minimum requirements of $\mathrm{CP}, \mathrm{P}, \mathrm{K}, \mathrm{Ca}, \mathrm{Mn}$ and $\mathrm{Fe}$ for beef cattle in lactation phase.
\end{abstract}

KEY-WORDS: forage legume, Leucaena leucocephala, silvopastoral system.

\section{INTRODUÇÃO}

Nos assentamentos rurais da Região Sudeste do Pará tem se verificado uma tendência a pecuarização, entretanto $\mathrm{o}$ inadequado estabelecimento e manejo das pastagens pode rapidamente evoluir para a degradação das mesmas (DIAS-FILHO, 2007). Refletindo na baixa produtividade animal, 
devido a escassez de alimentos ou na baixa qualidade do mesmo. Estudos com gramíneas forrageiras no Nordeste (BENDAHAN; VEIGA, 2003) e Sudeste (BITTENCOURT; VEIGA, 2003) do Pará revelaram baixos terores de proteína bruta (PB) e alguns minerais.

O uso de bancos forrageiros para corte com leguminosas arbóreas-arbustivas são considerados uma alternativa sustentável para suplementação animal (PEZO; IBRAHIM, 1999). As lenhosas forrageiras possuem boa produção, valor nutricional superior ao das gramíneas comumente utilizadas na região amazônica (acima de 20\% de PB), boa palatabilidade, resistência a seca e de fácil adaptação a solos de baixa fertilidade (SHELTON, 2001). Como exemplo pode-se citar a leucena (Leucaena leucocephala (Lam.) de Wit). Objetivou-se avaliar a qualidade nutricional da leucena em banco forrageiro para corte em estabelecimento familiar rural, comparando com os requerimentos mínimos exigidos por bovinos em fase de lactação.

\section{MATERIAL E MÉTODOS}

O estudo foi realizado no Projeto de Assentamento (P.A.) Belo Horizonte, situado no km 30 da BR-153, no município de São Domingos do Araguaia, na microrregião de Marabá. O clima local é Afi no limite de transição para Awi com temperatura média anual de 28,0 ${ }^{\circ} \mathrm{C}$ (ALMEIDA, 2007). O solo predominante é latossolo vermelho amarelo distrófico com textura média.
Foi realizada a avaliação da qualidade nutricional da leucena proveniente de uma ação teste implantada em março de 2009, a partir de pesquisa ação desenvolvida no âmbito do projeto "Sistemas silvipastoris e agrossilvipastoris como alternativa para a sustentabilidade da pecuária na agricultura familiar da região de Marabá" com apoio financeiro da Fundação de Amparo a Pesquisa do Estado do Pará (FAPESPA). O banco forrageiro para corte foi implantado em uma área de $400 \mathrm{~m}^{2}$, com espaçamento de $3 \mathrm{~m} \times 1$ m. A área tinha como vegetação dominante floresta primária, que foi desflorestada para a formação de pastagem aproximadamente 20 anos - inicialmente com o quicuio (Brachiaria humidicola (Rendle) Schweick) que há 10 anos foi substituído pelo capim estrela (Cynodon sp.). $\quad \mathrm{Na}$ Tabela 1 estão dispostas as características físicas e químicas do solo da área escolhida para a implantação da ação teste.

Para realizar a avaliação da qualidade nutricional da leucena, foram demarcadas três parcelas com três plantas em cada sendo consideradas como repetição. O material foi cortado em março de 2010 (período chuvoso) com faca de aço inoxidável a $70 \mathrm{~cm}$ do solo. As amostras foram pesadas e da mesma retirou-se uma sub-amostra de $500 \mathrm{~g}$ que foram separadas em fração não utilizável (caule $\geq 1$ $\mathrm{cm}$ ) e fração utilizável (folhas, vagem e galhos $\leq 1 \mathrm{~cm}$ ). Essas sub-amostras foram pesadas e secas em estufa a $60^{\circ} \mathrm{C}$ para a determinação do 
peso seco no Laboratório de Agronomia da Faculdade de Ciências Agrárias de Marabá. Após a secagem em estufa foram trituradas em moinho tipo Willey no Laboratório de Química do Campus II da UFPA, Marabá. Para a determinação dos macronutrientes $(\mathrm{N}, \mathrm{P}, \mathrm{K}$,
$\mathrm{Ca}, \mathrm{Mg})$ e micronutrientes $(\mathrm{Cu}, \mathrm{Fe}, \mathrm{Mn}, \mathrm{Zn})$ as amostras foram enviadas ao laboratório de solos da EMBRAPA Amazônia Oriental em Belém-PA. A proteína bruta foi calculada a partir do Nitrogênio total.

Tabela 1. Características físicas e químicas do solo de ação-teste silvipastoril com leucena, na camada de 0-20 cm, em lote de agricultor familiar no P. A. Belo Horizonte, São Domingos do Araguaia, Pará.

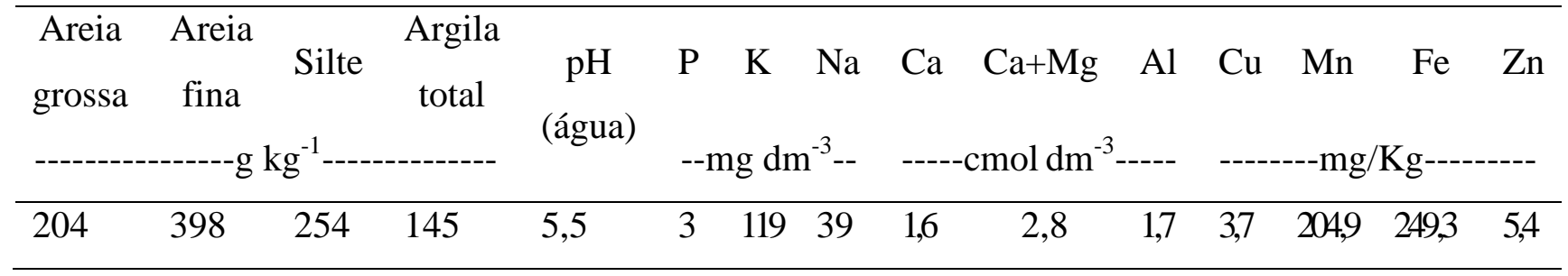

O delineamento experimental foi 0 inteiramente casualizado considerando o efeito da fração utilizável e não utilizável da forragem nas concentrações de macronutrientes e micronutrientes presentes na mesma. Para análise de variância utilizouse o método dos mínimos quadrados e o teste F ao nível de 5\% para verificar a significância dos efeitos. E o teste Tukey ao nível de 5\% para a comparação das médias. As análises estatísticas seguiram as recomendações de Furtado (2000) e foi utilizado o software SISVAR.

\section{RESULTADOS E DISCUSSÃO}

As médias do teor de PB, macronutrientes e micronutrientes na leucena estão dispostas na Tabela 2. Com respeito à proteína bruta, os teores encontrados na fração utilizável da leucena foram superiores aos encontrados na gramínea forrageira $B$. brizantha no Pará (BENDAHAN; VEIGA, 2003; BITTENCOURT; VEIGA， 2003). Entretanto esses teores foram considerados abaixo do que a literatura cita em outros países tropicais com teores acima de $20 \%$ (CEBALLOS, 2003 apud CASTRO et al., 2009) em sistemas silvipastoris intensivos com o uso de fertilizantes nitrogenados. Mesmo assim, considerou-se satisfatório o teor de PB no banco forrageiro avaliado nas condições da agricultura familiar local.

$\mathrm{O}$ conteúdo dos macrominerais $\mathrm{P}, \mathrm{Ca}$, $\mathrm{Mg}$ na FU da leucena foi superior ao encontrado na B. brizantha no estado do Pará (MANESCHY et al., 2005a). Mas apesar do P 
antender aos requerimentos nutricionais mínimos de bovinos de corte fase de lactação, observa-se que o baixo teor presente na leucena reflete a concentração desse mineral no solo. O conteúdo de $\mathrm{Ca}$ atendeu ao requerimento de bovinos de corte em fase de lactação (NRC, 2000). A baixa concentração de $\mathrm{Mg}$ presente na planta pode ter sido em função da concentração de $\mathrm{K}$ que durante o período chuvoso tende a se elevar, pois segundo Malavolta et al. (1997) esses minerais são antagônicos.

$\mathrm{O}$ conteúdo de $\mathrm{Cu}$ foi superior ao encontrado na $B$. brizantha (MANESCHY et al., 2005b). Mn e Fe atenderam aos requerimentos nutricionais para bovinos de corte em fase de lactação. $\mathrm{Mas} \mathrm{Mg}, \mathrm{Cu}$ e $\mathrm{Zn}$ não atenderam os requerimentos mínimos carecendo de suplementação (NRC, 2000). Segundo McDowell (1997) as deficiências minerais podem causar efeitos negativos nos aminais: $\mathrm{Mg}$ pode causar Tetania hipomagnesêmica levando o animal a morte; a falta de $\mathrm{Cu}$ pode ocasionar o crescimento retardado; e no caso do $\mathrm{Zn}$ distúrbios na pele, inchação de cascos, crescimento testicular reduzido e prostração.

Tabela 2. Valores médios de proteína bruta (PB), macronutrientes e micronutrientes presentes na fração utilizável (FU) e fração não utilizável (FN) da Leucena leucocephala no período chuvoso do ano (Março/2010), em banco forrageiro de propriedade familiar, São Domingos do Araguaia - PA.

\begin{tabular}{|c|c|c|c|c|c|c|c|c|c|}
\hline \multirow[t]{2}{*}{ Forragem } & PB & $\mathrm{P}$ & $\mathrm{K}$ & $\mathrm{Ca}$ & $\mathrm{Mg}$ & $\mathrm{Cu}$ & $\mathrm{Mn}$ & $\mathrm{Fe}$ & $\mathrm{Zn}$ \\
\hline & $\%$ & \multicolumn{4}{|c|}{-----------------------g/kg------------------ } & \multicolumn{4}{|c|}{-------------------mg/kg-------------------- } \\
\hline Leucena FU & $13,40 \mathrm{a}$ & $2,52 \mathrm{a}$ & $11,02 \mathrm{a}$ & $6,31 \mathrm{a}$ & $4,17 \mathrm{a}$ & $9,26 \mathrm{a}$ & $80,75 a$ & $139,12 \mathrm{a}$ & $26.32 \mathrm{a}$ \\
\hline Leucena FN & $4,61 b$ & $2,62 \mathrm{a}$ & $9,93 b$ & $4,71 \mathrm{a}$ & $2,80 \mathrm{~b}$ & $5,42 b$ & $32,13 b$ & $148,52 \mathrm{a}$ & $28.36 \mathrm{a}$ \\
\hline $\mathrm{CV}(\%)$ & 13,14 & 15,59 & 4,00 & 26,24 & 4,88 & 12,33 & 25,92 & 22,80 & 9,41 \\
\hline Brachiaria brizantha & $5,8-6,8$ & 1,10 & 12,1 & 3,90 & 2,90 & 4,41 & 321,53 & 353,36 & 43,35 \\
\hline Requerimento $^{2}$ & $7,18-10,00$ & $2,20-3,80$ & $1,60-2,40$ & 2,00 & 7,00 & 10 & 40 & 50 & 30 \\
\hline
\end{tabular}

Médias seguidas pela mesma letra na coluna não diferem significativamente pelo teste Tukey a $5 \%$ de probabilidade.

${ }^{1}$ Onde: PB (BITTENCOURT; VEIGA, 2003), macrominerais e microminerais (MANESCHY et al., 2005a; MANESCHY et al., 2005b), CV = Coeficiente de variação.

${ }^{2}$ Requerimentos de acordo as recomendações para bovinos de corte em fase de lactação (NRC, 2000).

É importante ressaltar que esses dados se referem ao período chuvoso do ano, e em forrageiras tropicais a restrição de água durante o período seco do ano provoca alterações fisiológicas nas plantas e, por conseguinte na absorção de nutrientes. Portanto para obter uma resposta mais contundente sobre o estudo da qualidade nutricional em banco forrageiro sob as condições da agricultura familiar no Sudeste paraense faz-se necessária a comparação desses resultados com uma avaliação durante o período seco do ano.

\section{CONCLUSÕES}

A avaliação da leucena durante o período chuvoso do ano demonstrou que a 
fração utilizável dessa forrageira atendeu aos requerimentos mínimos de $\mathrm{PB}, \mathrm{P}, \mathrm{K}, \mathrm{Ca}, \mathrm{Mn}$ e Fe para bovinos de corte em fase de lactação. Sendo que os teores de PB, Ca, Mg e $\mathrm{Cu}$ foram superiores as gramíneas comumente utilizadas no estado do Pará. Considera-se que a utilização de bancos forrageiros de leucena podem auxiliar a suplementar as necessidades animais, contribuindo com a sustentabilidade dos sistemas de criação com dupla-aptidão praticados por agricultores familiares no Sudeste Paraense.

\section{REFERÊNCIAS}

ALMEIDA, M. F. de. Caracterização agrometeorológica do município de Marabá. 2007. 77 f. Trabalho de Conclusão de Curso (Agronomia) - Faculdade de Ciências Agrárias de Marabá, Universidade federal do Pará, Marabá, 2007.

BENDAHAN, A. B.; VEIGA, J. B. da. Características das pastagens em propriedades leiteiras da Microrregião de Castanhal, Estado do Pará, Brasil. In: TOURRAND, J. F.; VEIGA, J. B. (Org.). Viabilidade de sistemas agropecuários na agricultura familiar da Amazônia. Belém: Embrapa, 2003. p. 79-101.

BITTENCOURT, P. C. S.; VEIGA, J. B. da. Situação das pastagens em sistemas de produção leiteira da agricultura familiar do município de Uruará-PA, Região da Transamazônica. In: TOURRAND, J. F.; VEIGA, J. B. (Org.). Viabilidade de sistemas agropecuários na agricultura familiar da Amazônia. Belém: Embrapa, 2003. p. 103-117.

CASTRO, C. H. M.; DURÁN, C. H. M.; DURÁN, E. J. M.; DURÁN, J. P. M. Carne, Leche y Mejor Ambiente em El Sistema Silvopastoril Intensivo com Leucaena leucocephala (Lam.) de Wit MIMOSACEAE. In: MURGUEITIO, E. R.; CUARTAS, C. A. C.; NARANJO, J. F. R. Ganadería del futuro: Investigación para el desarrollo. Cali, Colômbia: Fundación CIPAV, 2009. p. 41-66.

DIAS-FILHO, M. B. Degradação de pastagens: processos, causas e estratégias de recuperação. Belém: Embrapa Amazônia Oriental, 2007. 190 p.

FURTADO, D. F. Sistema de análise estatística para dados balanceados. Lavras: UFLA/DEX/SISVAR, 2000. 145 p.

MCDOWELL, L. R. Minerais para ruminantes sob pastejo em regiões tropicais, enfatizando o Brasil. 3 ed. Gainesville: University of Florida, 1999. 92 p. MALAVOLTA, E.; VITTI, G. C.; OLIVEIRA, S. A. Avaliação do estado nutricional das plantas: princípios e aplicações. 2 ed. Piracicaba: POTAFOS, 1997. 319 p. 
de sustentabilidade para áreas tropicais $\mathrm{e}$

MANESCHY, R. Q.; CARDOSO, E. de C.; VEIGA, J. B. da.; MCDOWELL, L. R. Effect of Season on Mineral Concentrations of Braquiaria (Brachiaria Brizantha cv. Marandu) in Dairy Cattle Farms of Eastern Amazon. I. Macrominerals. Journal of Animal and Veterinary Advances, v. 4, n. 1, p. 118-122. 2005a.

MANESCHY, R. Q.; CARDOSO, E. de C.; VEIGA, J. B. da.; MCDOWELL, L. R. Effect of Season on Mineral Concentrations of Braquiaria (Brachiaria Brizantha cv. Marandu) in Dairy Cattle Farms of Eastern Amazon. II. Microminerals. Journal of Animal and Veterinary Advances, v. 4, n. 1, p. $123-125.2005$ b.

NRC. NATIONAL RESEARCH COUNCIL.

Nutrient requerements of beef cattle.

Washington: National Academy of science, 2000. 248 p.

PEZO, D.; IBRAHIM, M. Sistemas Silvopastoriles. 2 ed. Turrialba, Costa Rica: CATIE, 1999. 276 p. (Materiales de enseñanza, n. 44).

SHELTON, H. M. Potenciais e limitações de Leucaena spp. para uso em sistemas silvipastoris. In: CARVALHO, M. M.; ALVIM, M. J.; CARNEIRO, J. C. (Ed.). Sistemas agroflorestais pecuários: opções subtropicais. Juiz de Fora: Embrapa Gado de Leite, Brasília: FAO, 2001. p. 379 - 398. 